\title{
Modeling of the boiler economizer
}

\author{
Marcin Trojan ${ }^{1, *}$, and Mariusz Granda ${ }^{1}$ \\ ${ }^{1}$ Institute of Thermal Power Engineering, Cracow University of Technology, Cracow, Poland
}

\begin{abstract}
The boiler economizer is a tube heat exchanger located in the final part of the convective duct. In the economizer, water flowing into the boiler is preheated by flue gases. The paper presents the boiler economizer mathematical model with distributed parameters, which can be used to simulate its operation. The developed mathematical model makes it possible to determine temperatures of the tube and working medium of the boiler economizer. In addition, the non-linear mathematical model of the entire boiler allows to analyze the influence of ash fouling of individual boiler heating surfaces on the economizer operation. The proposed model can also be used for monitoring heat and flow parameters of the economizer in on-line mode.
\end{abstract}

\section{Introduction}

The subject of this paper is the boiler economizer mathematical model which can be applied in the economizer design and operation calculations.

Literature in the field of hydraulic and thermal boiler calculations is huge. Both analytical methods and modeling CFD are used for mathematical modeling of processes in boilers [1,2]. Computational modeling is an excellent way to optimize boiler design and performance. However, analytical methods are more suitable to monitor the operation of the boiler on-line. The reason for this is the computation time of CFD simulations. A lot of attention is paid in the literature to modeling of steam superheaters. The complexity of heat transfer processes in the steam superheaters causes some difficulties in mathematical modeling of superheaters. The steam superheater cannot be calculated using the method based on the logarithmic mean temperature difference between the fluids (the LMTD method) or the $\varepsilon$-NTU method (effectiveness - the number of transfer units). It is caused by a large dependence of the water steam specific heat on pressure and temperature [3-5]. In works $[6,7]$ a standard method for calculating steam boilers was presented. In this method, superheaters are calculated as common heat exchangers assuming constant physical properties of the liquid.

Jan Taler et al. [8] proposed a transient mathematical model for the combustion chamber for the optimization of the plant start-up time. In the work [9] also discuss the optimal boiler start-up by using mathematical models of the critical pressure components of a steam boiler.

Corrosion of economizer tubes is the subject of many works $[10,11]$. The available literature contains a little information about the economizer modeling. In the work [12] models of economizer with smooth ducts and economizer ducts embossed with turbulence inducing ribs were presented. Stevanovic et al. [13] proposed the numerical model which allows to demonstrate how the high-pressure economizer can be used to raise the primary control reserve in coal-fired thermal power plants.

\section{Mathematical model of the boiler economizer}

Having passed through steam superheaters, flue gases are directed onto the boiler economizer, located in the final part of the convective duct. The economizer is a tube heat exchanger where water flowing into the boiler is preheated by flue gases. Thereby, the flue gas temperature is reduced (flue gas waste heat recovery).

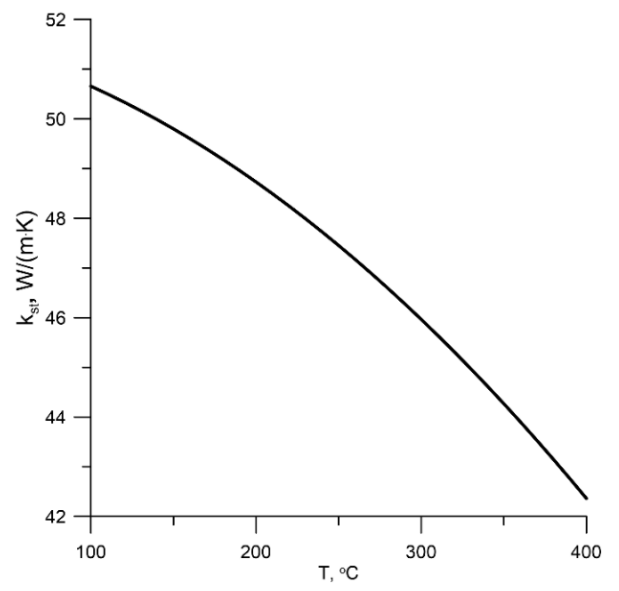

Fig. 1. Temperature-dependent changes in the heat conductivity coefficient for steel 20 .

The OP-210M boiler has a two-stage economizer made of tubes arranged in a staggered configuration. The economizer tubes are made of Russian steel 20, whose heat conductivity coefficient is approximated using the relation

\footnotetext{
* Corresponding author: marcin.trojan@pk.edu.pl
} 
$k_{w}=35.762267-6.01214 \cdot 10^{-7} T^{2.5}$

where $k_{w}$ is in $\mathrm{W} /(\mathrm{m} \cdot \mathrm{K})$ and $\mathrm{T}$ in ${ }^{\circ} \mathrm{C}$.

Temperature-dependent changes in the heat conductivity coefficient for steel 20 are shown in Fig. 1. The economizer first and second stage are made of tubes connected with fins along the entire length (membrane heating surface). Due to the temperature field symmetry, the economizer tubes can be treated as longitudinally finned ones (Fig. 2).

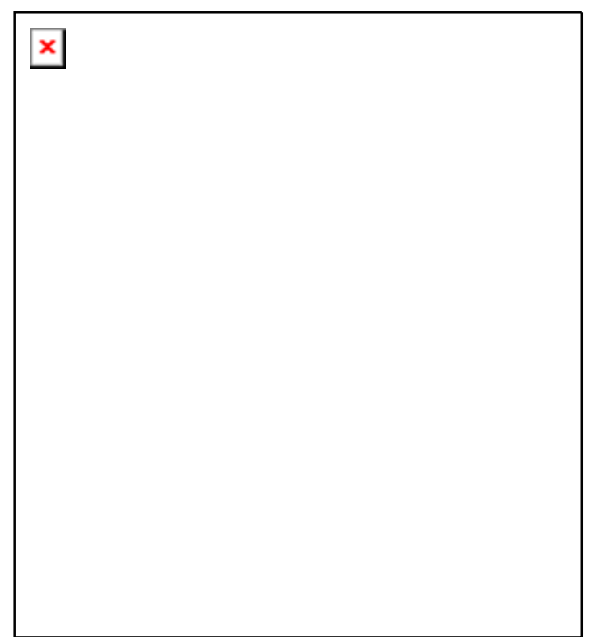

Fig. 2. The economizer longitudinally finned tube.

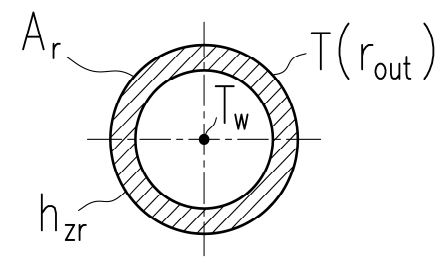

Fig. 3. Equivalent smooth tube taking account of fins located on the flue gas side.

Basic data concerning the economizer first and second stage are listed in Table 1.

Table 1. Basic data of the economizer first and second stage.

\begin{tabular}{|l|c|c|}
\hline \multicolumn{1}{|c|}{ Basic data } & stage I & stage II \\
\hline $\begin{array}{l}\text { Surface area of tubes } \\
\text { with no fins, } \mathrm{m}^{2}\end{array}$ & 733.5 & 1107.5 \\
\hline Number of smooth tubes & 76 & 54 \\
\hline Tube length, m & 96 & 204 \\
\hline Number of tube rows & 12 & 25 \\
\hline $\begin{array}{l}\text { Tube pitch (transverse } \\
\text { pitch } s_{1} \times \text { longitudinal } \\
\text { pitch } s_{2} \text { ), mm }\end{array}$ & $90 \times 50$ & $130 \times 50$ \\
\hline $\begin{array}{l}\text { Outer diameter } \times \text { tube } \\
\text { wall thickness, mm }\end{array}$ & $32 \times 5$ & $32 \times 5$ \\
\hline Fin width $\mathrm{x}$ fin & $68 \times 4$ & $68 \times 4$ \\
\hline
\end{tabular}

\begin{tabular}{|l|c|c|}
\hline thickness, $\mathrm{mm}$ & & \\
\hline Tube and fin material & $\mathrm{B} 18$ & $\mathrm{~B} 18$ \\
\hline $\begin{array}{l}\text { Flue gas flow free cross- } \\
\text { section, } \mathrm{m}^{2}\end{array}$ & 17.7 & 21.8 \\
\hline Flow nature & Counterflow & Counterflow \\
\hline
\end{tabular}

The economizer mathematical modeling is similar to modeling the steam superheater. However, it has to be taken into account that the working medium flowing in tubes is water. It should also be emphasized that due to high specific heat of this medium, the heat flux that has to be supplied to water from flue gases is very high. The presence of fins on the superheater tubes will be taken into consideration by introducing an equivalent (weighted) heat transfer coefficient on the flue gas side.

The weighted heat transfer coefficient on the flue gas side related to the outer surface of a smooth tube (with no longitudinal fins) is determined from the condition of equality between the heat flux absorbed by the outer surface of the smooth tube (assuming that the heat transfer coefficient is equal to the weighted one) and the total heat flux absorbed by the fins and the smooth tube surface in between the fins (Fig. 2 and Fig. 3)

$$
\begin{aligned}
& h_{z r} A_{r}\left[T\left(r_{\text {out }}\right)-T_{g}\right]= \\
& =h_{g} A_{r m}\left[T\left(r_{\text {out }}\right)-T_{g}\right]+h_{g} A_{\text {fin }} \eta_{\text {fin }}\left[T\left(r_{\text {out }}\right)-T_{g}\right]
\end{aligned}
$$

The symbols in Eq. (2) are as follows: $h_{z r}-$ weighted heat transfer coefficient, flue gas side, $\left(\mathrm{W} / \mathrm{m}^{2} \mathrm{~K}\right), h_{g}$ - heat transfer coefficient, flue gas side, $\left(\mathrm{W} / \mathrm{m}^{2} \mathrm{~K}\right)$,

$\eta_{\text {fin }}$ - fin efficiency, $A_{r}$ - smooth tube outer surface area $\left(\mathrm{m}^{2}\right), A_{r m}$ - smooth tube surface area in between the fins $\left(\mathrm{m}^{2}\right), A_{\text {fin }}$ - fin surface area $\left(\mathrm{m}^{2}\right), T\left(r_{\text {out }}\right)$ - tube outer surface temperature $\left({ }^{\circ} \mathrm{C}\right), T_{g}$ - flue gas temperature $\left({ }^{\circ} \mathrm{C}\right)$.

After transformations, Eq. (2) gives the following relation for the weighted heat transfer coefficient on the flue gas side

$$
h_{z r}=h_{g}\left[\frac{A_{r m}}{A_{r}}+\eta_{f i n}\left(h_{g}\right) \frac{A_{f i n}}{A_{r}}\right]
$$

The efficiency of a straight fin with constant thickness is expressed as [14-17]

$$
\eta_{f i n}=\frac{\operatorname{tgh}\left(m H_{z}\right)}{m H_{z}}
$$

where parameter $m$ is described using the following equation 


$$
m=\sqrt{\frac{2 h_{g}}{k_{f i n} \delta_{f i n}}}
$$

and the fin height is found from the relation (Fig. 2)

$$
H_{z}=\frac{s_{\text {fin }}}{2}-r_{\text {out }} \cos \varphi
$$

Surface areas $A_{f i n}, A_{r}, A_{r m}$, are defined by the following formulae

$$
\begin{aligned}
& A_{\text {fin }}=4\left(\frac{s_{\text {fin }}}{2}-b\right)=4 \cdot H_{z} \\
& A_{r}=2 \pi r_{\text {out }} \\
& A_{r m}=(2 \pi-4 \varphi) r_{\text {out }}
\end{aligned}
$$

Angle $\varphi$ is calculated from (Fig. 2)

$$
\varphi=\arcsin \left(\frac{\delta_{\text {fin }}}{2 r_{\text {out }}}\right)
$$

Using the weighted heat transfer coefficient $h_{z r}$, the economizer is calculated as if it was made of smooth tubes.

For the staggered tube arrangement, the Nusselt number is found from the following relation [18]

$N u=0.196 \sigma_{1}^{-0.247} \sigma_{2}^{-0.051} \operatorname{Re}^{0.674} \operatorname{Pr}^{0.44}$

where

$\sigma_{1}=\frac{s_{1}}{d}$ and $\sigma_{2}=\frac{s_{2}}{d}$

The water side Nusselt number was calculated using Gnielinski's correlation [19]

$$
\mathrm{Nu}=\frac{\frac{\xi}{8}(\operatorname{Re}-1000) \operatorname{Pr}}{1+12.7 \sqrt{\frac{\xi}{8}}\left(\operatorname{Pr}^{2 / 3}-1\right)}\left[1+\left(\frac{d_{i n}}{L}\right)^{2 / 3}\right]\left(\frac{\operatorname{Pr}}{\operatorname{Pr}_{i n}}\right)^{0.11}
$$

$4 \cdot 10^{3} \leq \operatorname{Re} \leq 10^{6} \quad 0.5 \leq \operatorname{Pr} \leq 200$

where the friction factor for smooth tubes is given by the Filonienko equation [20]

$$
\xi=(1.82 \log \mathrm{Re}-1.64)^{-2}
$$

The heat transfer coefficient at the tube inner surface for transition regime from laminar to turbulent and for turbulent flow can also be determined using the correlation proposed by Taler [21]

$$
\begin{aligned}
& \mathrm{Nu}=\mathrm{Nu}_{m, q}(\mathrm{Re}=2300)+\frac{\frac{\xi}{8}(\mathrm{Re}-2300) \operatorname{Pr}^{1.008}}{1.08+12.39 \sqrt{\frac{\xi}{8}}\left(\operatorname{Pr}^{2 / 3}-1\right)} \\
& \times\left[1+\left(\frac{d_{\text {in }}}{L}\right)^{2 / 3}\right]\left(\frac{\mathrm{Pr}}{\operatorname{Pr}_{\text {in }}}\right)^{0.11}, \\
& 2300 \leq \operatorname{Re} \leq 10^{6}, \quad 0.1 \leq \operatorname{Pr} \leq 1000, \quad \frac{d_{\text {in }}}{L} \leq 1
\end{aligned}
$$

where: $d_{i n}$ - inner diameter of the tube, $L$ - tube length.

The mean Nusselt number for laminar flow $N u_{m}$ with respect to tube length $L$ can be expressed for uniform wall heat as [21]

$$
\begin{aligned}
& \mathrm{Nu}_{m, q}=\left(\mathrm{Nu}_{m, q, 1}^{4.8290}+\mathrm{Nu}_{m, q, 2}^{4.8290}\right)^{(1 / 4.8290)} 1 \cdot 10^{-6} \\
& \leq \frac{1}{\operatorname{RePr}} \frac{x}{d_{i n}} \leq 1.0
\end{aligned}
$$

The symbol $N u_{m, q, 1}$ in Eq. (16) denotes the mean Nusselt number for hydrodynamically and thermally fully developed flow

$$
\mathrm{Nu}_{m, q, 1}=\frac{48}{11}=4.364
$$

The symbol $N u_{m, q, 2}$ denotes the mean Nusselt number for hydrodynamically and thermally fully developed flow over the plate with linear temperature profile in the fluid and constant heat flux at the wall surface

$$
\begin{aligned}
& \mathrm{Nu}_{\mathrm{m}, \mathrm{q}, 2}=3^{1 / 3} \Gamma(2 / 3)\left(\operatorname{Re} \operatorname{Pr} \frac{d_{\text {in }}}{L}\right)^{1 / 3} \\
& =1.9530\left(\operatorname{Re} \operatorname{Pr} \frac{d_{\text {in }}}{L}\right)^{1 / 3}, \frac{1}{\operatorname{Re} \operatorname{Pr}} \frac{L}{d_{i n}} \leq 0.0005
\end{aligned}
$$

where the symbol $\Gamma$ designates the gamma function [22].

Eq. (18) is valid only for the initial section of the entrance region when the parameter $\frac{1}{\operatorname{Re} \operatorname{Pr}} \frac{L}{d_{i n}}$ is small. The coefficient of determination $r^{2}$ and the absolute maximum error $\left|\varepsilon_{\max }\right|$ for formula (16) are $r^{2}=0.99979$ and $\left|\varepsilon_{\max }\right| \leq 3.9 \%$.

The economizer was modeled in the same way as the superheaters, using the developed distributed parameter mathematical model proposed in [23, 24]. The general assumptions made in the development of a numerical model of the boiler economizer are as follows: the water and gas flow is one dimensional, the physical properties of fluids are functions of temperature, axial heat conduction in the tube wall and fluid is negligible, the temperature and flue gas velocity are constant over the channel cross-section before the economizer, and heat transfer coefficients on the inner and outer tube surfaces 
are uniform. By using the partial differential equations describing the space and time changes of steam $T_{s}$, tube wall $T_{w}$, ash layer $T_{a}$ and flue gas temperatures $T_{g}$ can be obtained

- the steam temperature at the outlet of the control volume (Fig. 4)

$$
\begin{aligned}
& T_{s, i+1}=T_{w 1, i}-\left(T_{w 1, i}-T_{s, i}\right) \exp \left(-\Delta N_{s, i+\frac{1}{2}}\right), \\
& i=1, \ldots, N
\end{aligned}
$$

where the symbol $\Delta N_{s, i+\frac{1}{2}}$ denotes the number of transfer units on the steam side for the $i$-th control volume, defined as

$$
\Delta N_{s, i+\frac{1}{2}}=\frac{2 \pi r_{i n} h_{s, i} \Delta x}{\dot{m}_{s} \bar{c}_{p_{s, i}}}
$$

- $\quad$ the system of three nonlinear algebraic equations for tube wall temperatures $T_{w 1, i}, T_{w 2, i}$ and $T_{w 3, i}$

$$
\begin{aligned}
& T_{w 1, i}=\frac{1}{h_{s, i} d_{i n}+\frac{k_{w}\left(T_{w 1, i}\right)+k_{w}\left(T_{w 2, i}\right)}{2} \frac{d_{c}}{\delta_{w}}} \\
& \times\left[h_{s, i} \bar{T}_{s, i} d_{i n}+\frac{k_{w}\left(T_{w 1, i}\right)+k_{w}\left(T_{w 2, i}\right)}{2} \frac{d_{c}}{\delta_{w}} T_{w 2, i}\right], \\
& i=1, \ldots, N
\end{aligned}
$$

$$
\begin{aligned}
& T_{w 2, i}=\frac{1}{\frac{k_{w}\left(T_{w 1, i}\right)+k_{w}\left(T_{w 2, i}\right)}{2} \frac{d_{c}}{\delta_{w}}+\frac{k_{a}}{\delta_{a}} d_{s}} \\
& \times\left[\frac{k_{w}\left(T_{w 1, i}\right)+k_{w}\left(T_{w 2, i}\right)}{2} \frac{d_{c}}{\delta_{w}} T_{w 1, i}+k_{a} \frac{d_{s}}{\delta_{a}} T_{w 3, i}\right], \\
& i=1, \ldots, N
\end{aligned}
$$$$
T_{w 3, i}=\frac{1}{\left[h_{g, i}\left(d_{o}+2 \delta_{a}\right)+k_{a} \frac{d_{s}}{\delta_{a}}\right]}
$$$$
\times\left[h_{g, i}\left(d_{o}+2 \delta_{a}\right) \bar{T}_{g, i}+k_{a} \frac{d_{s}}{\delta_{a}} T_{w 2, i}\right],
$$$$
i=1, \ldots, N
$$

where:

$$
d_{c}=\left(d_{i n}+d_{o}\right) / 2=r_{i n}+r_{o}, \quad d_{s}=d_{o}+\delta_{a}=2 r_{o}+\delta_{a} .
$$

- the flue gas temperature at the outlet of the control volume

$$
T_{g, i}^{\prime \prime}=T_{w 3, i}-\left(T_{w 3, i}-T_{g, i}^{\prime}\right) \exp \left(-\Delta N_{g, i}\right), \quad i=1, \ldots, N
$$

where the symbol $\Delta N_{g, i}$ denotes the number of transfer units on the gas side for the $i$-th control volume, defined as

$\Delta N_{g, i}=\frac{2 \pi\left(r_{o}+\delta_{a}\right) \Delta x h_{g, i}}{\dot{m}_{g} \bar{c}_{p_{g, i}}}$

where $\Delta x$ is the control volume length.

The resulting system of nonlinear algebraic equations (19), (21) - (23), and (24) for the temperatures at nodes in steam, wall, and flue gas areas was solved by the Gauss-Seidel method.

a)

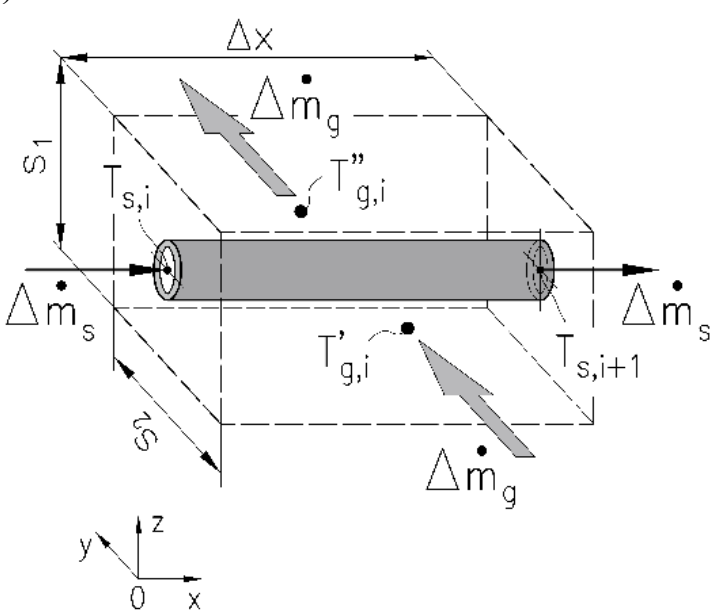

b)

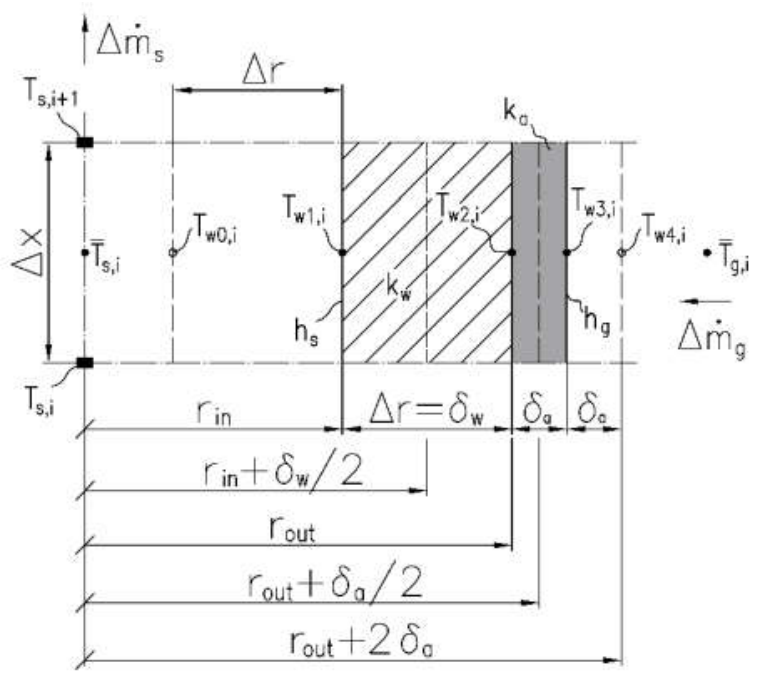

Fig. 4. Finite control volume: (a) for the flue gas and steam (b) for the tube wall.

\section{Results of modeling the operation of the economizer second stage}

From the economizer first stage, the boiler feed water is directed to the economizer second stage. In terms of the 
flue gas flow direction, the heater is located in the flue gas duct downstream the economizer first stage.

The economizer second stage is made of 54 rows, with twenty-five tubes with outer diameter $d_{o}=32 \mathrm{~mm}$ and wall thickness $\delta_{E C O}=5 \mathrm{~mm}$ each (Fig. 5).

A mathematical model of the device was developed. The flow arrangement and division of the economizer second stage into finite volumes is shown in Fig. 6. Considering the flow arrangement, the economizer second stage can be classified as a parallel-cross-flow heat exchanger. The economizer tubes are in a staggered configuration. The tube arrangement is shown in Fig. 5.

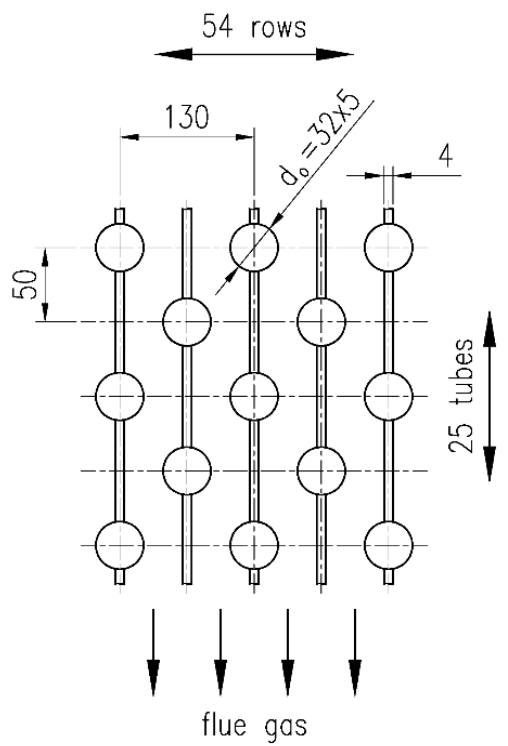

Fig. 5. Staggered tube arrangement in the economizer second stage.

The symbols A1-AN, B1-BN and C1-CN in Fig. 6 denote the temperature of the inner and outer tube surfaces, and the outer temperature of the ash deposit, respectively:

A1 $=$ RPWD11(1), $\quad$ RPWD12(1), RPWD13(1);
A2 $=$ RPWD11(2), RPWD12(2), RPWD13(2);

$\mathrm{AI}=\mathrm{RPWD11}(\mathrm{I}), \quad \mathrm{RPWD12}(\mathrm{I}), \quad \mathrm{RPWD13}(\mathrm{I}) ; \quad \mathrm{AN}-$ 1=RPWD11(N-1), RPWD12(N-1), RPWD13(N-1);

AN=RPWD11(N), RPWD12(N), RPWD13(N);

B1=RPWD21(1), $\quad$ RPWD22(1), RPWD23(1); B2=RPWD21(2), RPWD22(2), RPWD23(2);

$\mathrm{BI}=\mathrm{RPWD} 21(\mathrm{I}), \quad \mathrm{RPWD} 22(\mathrm{I}), \quad$ RPWD23(I); $\quad$ AN1=RPWD21(N-1), RPWD22(N-1), RPWD23(N-1);

BN=RPWD21(N), RPWD22(N), RPWD23(N);

C1=RPWD251(1), $\quad$ RPWD252(1), RPWD253(1); C2=RPWD251(2), RPWD252(2), RPWD253(2);

CI=RPWD251(I), RPWD252(I), RPWD253(I);
CN-1=RPWD251(N-1), RPWD252(N-1), RPWD253(N$1)$;

\section{CN=RPWD251(N), RPWD252(N), RPWD253(N).}

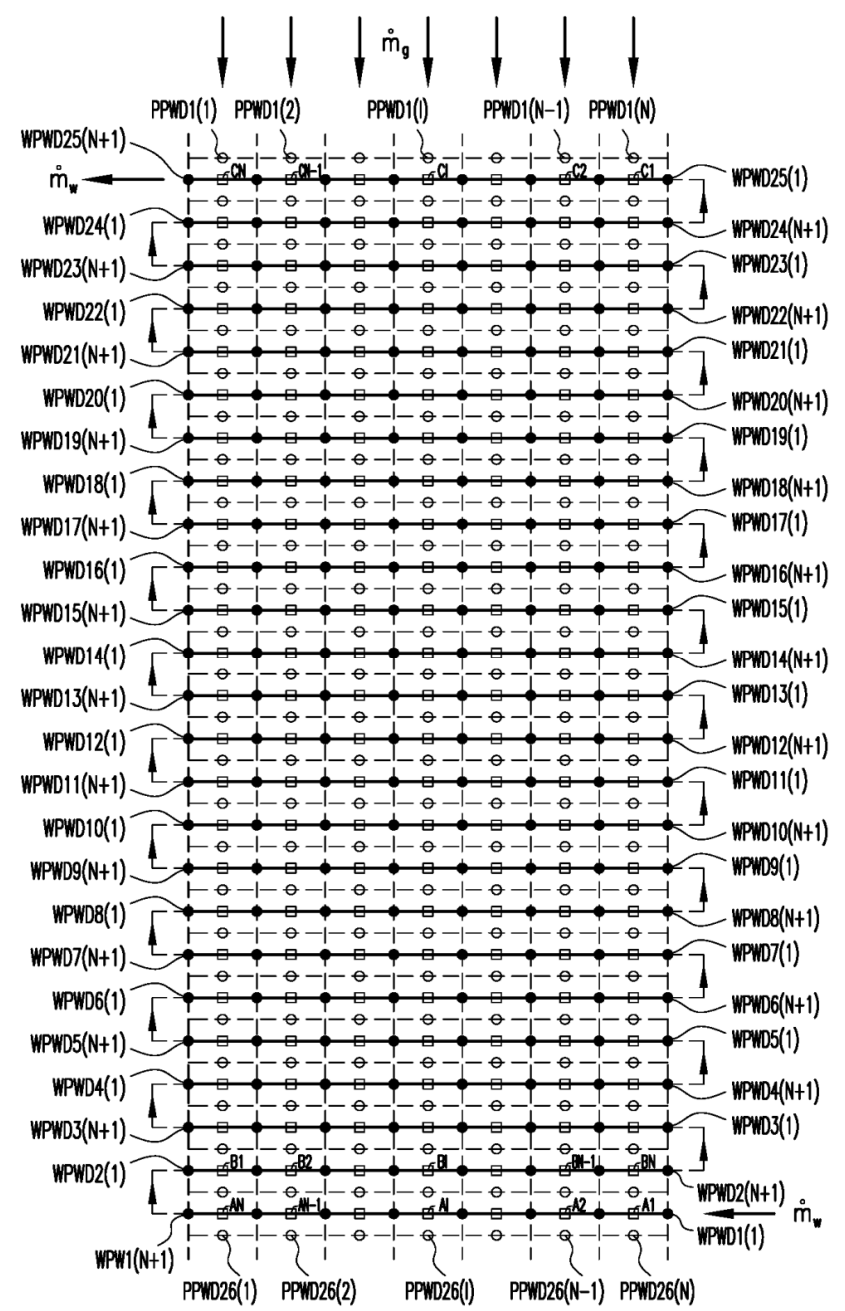

Fig. 6. Division of cross-parallel-flow the second stage of economizer with twenty-five passes into finite volumes: PPWD1(I), PPWD2(I), ... , PPWD26(I) - flue gas temperature, RPWD11(I), RPWD12(I), RPWD13(I), .., RPWD251(I), RPWD252(I), RPWD253(I) - temperature of the inner and outer tube surfaces, and the outer temperature of the ash deposit, respectively, WPWD1(I), WPWD2(I), ... WPWD25(I) - water temperature.

The following data are assumed in the economizer second stage model: $\delta_{\text {fin }}=4 \mathrm{~mm}, s=130 \mathrm{~mm}$, flue gas duct width $a_{d}=7700 \mathrm{~mm}$, flue gas duct height $b_{d}=75.45 \mathrm{~mm}=3375 \mathrm{~mm}$. The flue gas flow velocity is determined in the tube bank free cross-section. Considering the flue gas duct dimensions, the free crosssection surface area is $A_{d}=18,8 \mathrm{~m}^{2}$. Considering the gaps between the economizer and the duct walls, the free cross section area of $A_{d}=21,8 \mathrm{~m}^{2}$ is assumed, according to the data provided by the manufacturer. The equivalent thickness of the radiative layer is found from formula 


$$
\begin{aligned}
& S_{z}=\frac{3.6 \mathrm{~V}}{A} \\
& =3.6 \cdot \frac{\left[2 s_{1} s_{2}-\frac{\pi d_{o}^{2}}{2}-2\left(2 s_{2}-d_{o}\right) \delta_{f i n}\right]}{2 \pi d_{o}+2\left(2 s_{2}-d_{o}\right)}
\end{aligned}
$$

It totals $s_{z}=115.9 \mathrm{~mm}$. The economizer second stage flue gas and water mass flows are $\dot{m}_{g}=62.7 \mathrm{~kg} / \mathrm{s}$ and $\dot{m}_{w}=49.5 \mathrm{~kg} / \mathrm{s}$, respectively.

Fig. 7 presents the temperature distribution of flue gases flowing through the economizer first stage in two cases: (1) all the boiler heating surfaces are clean and (2) the boiler operates with steam superheaters affected by ash fouling.

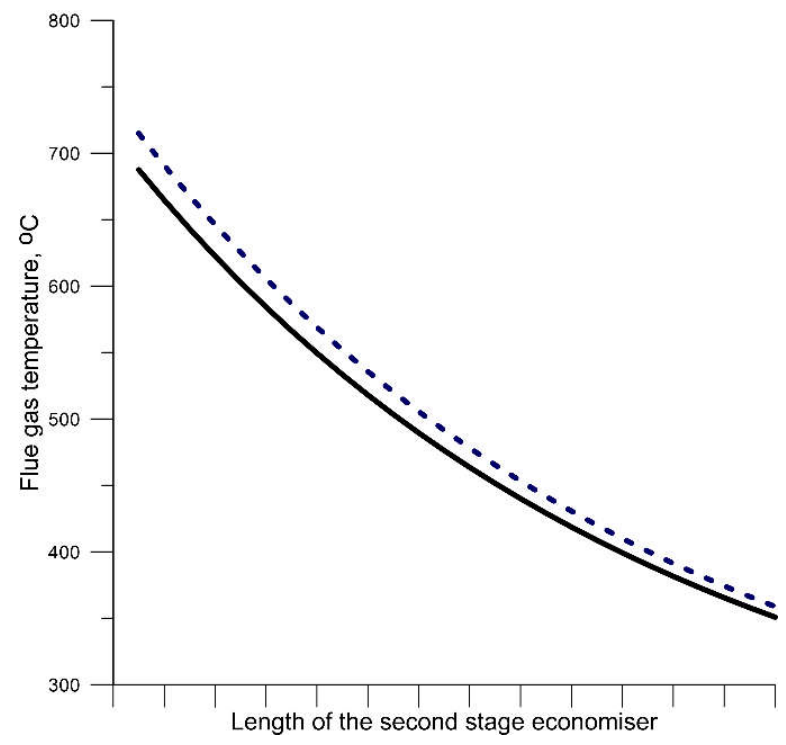

Fig. 7. Temperature distribution of flue gases flowing through the economizer second stage (continuous line - clean boiler, dashed line - individual steam superheater stages affected by ash fouling).

If the boiler heating surfaces are clean, the flue gas temperature upstream the economizer second stage is $687.7^{\circ} \mathrm{C}$. The water temperature at the economizer second stage inlet is $239.6{ }^{\circ} \mathrm{C}$ and equal to the water temperature at the economizer first stage outlet. The drop in the flue gas temperature for the boiler clean heating surfaces totals $336.7{ }^{\circ} \mathrm{C}$, which means that the temperature of flue gases downstream the economizer second stage is $351.0^{\circ} \mathrm{C}$, and this is equal to the flue gas temperature at the economizer first stage inlet. The water temperature at the economizer outlet (Fig. 8) is in this case $314.3^{\circ} \mathrm{C}$; consequently the increment in the temperature of water flowing through the economizer second stage totals $74.7^{\circ} \mathrm{C}$. The biggest increment in the water temperature, $4.4{ }^{\circ} \mathrm{C}$, is obtained in tube 25 , which is in the zone of the flue gas highest temperatures.
If the steam superheater individual stages are affected by ash fouling, the flue gas temperature upstream the economizer second stage is $715.0^{\circ} \mathrm{C}$, which is a value higher by $27.3{ }^{\circ} \mathrm{C}$ compared to the case with the boiler operation with clean steam superheaters. The water temperature at the economizer inlet is $240.5^{\circ} \mathrm{C}$. The flue gas temperature downstream the economizer second stage is $358.9{ }^{\circ} \mathrm{C}$, which means a drop by $356.1{ }^{\circ} \mathrm{C}$. Passing through the economizer second stage, water is heated to the temperature of $318.9^{\circ} \mathrm{C}$. The biggest increment in the water temperature, $4.5^{\circ} \mathrm{C}$, is obtained in tube 25 , which is in the zone of the flue gas highest temperatures.

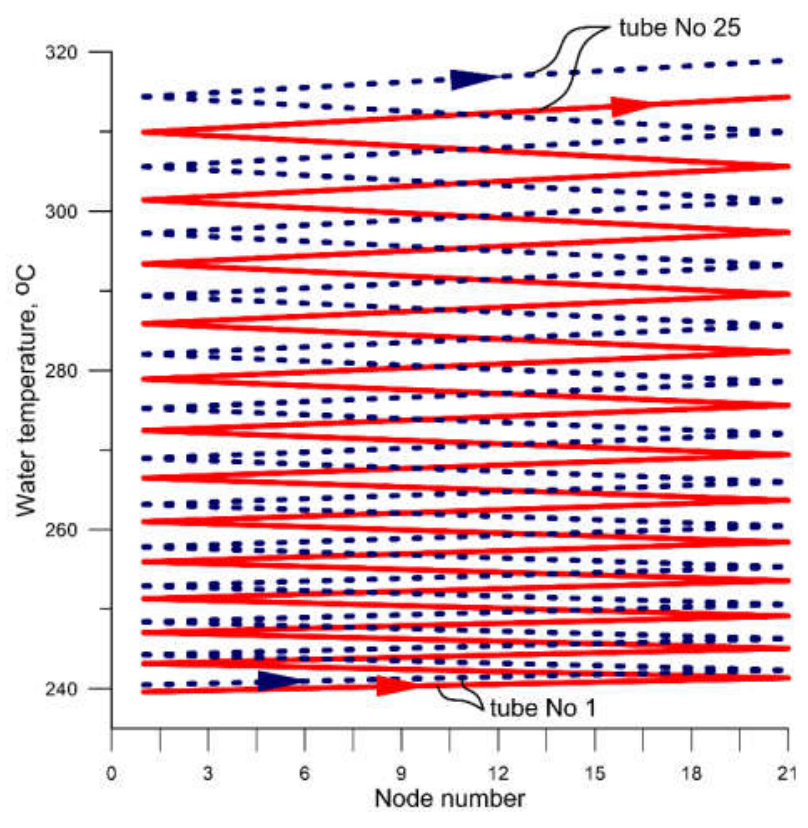

Fig. 8. Temperature distribution of water flowing through the economizer second stage (continuous line - clean boiler, dashed line - individual steam superheater stages affected by fouling).

\section{Conclusions}

The proposed mathematical model is suitable for modeling multi-pass boiler economizers and various flow systems. Due to the short calculation time, the method can be used for monitoring heat and flow parameters of the economizer in on-line mode. The developed mathematical model makes it also possible to determine temperatures of the tube outer and inner surfaces and external fouling for all heating surfaces of the boiler.

The developed mathematical model allows to determine parameters of working mediums and the temperature of the wall, which is essential in design calculations. The knowledge of the metal temperature under the different boiler loads enables a correct selection of the steel grade. Determining the tube walls temperature also makes it possible to avoid overheating of the tubes, e.g. at the boiler low loads. 
The proposed method can be used to model plate fin and tube heat exchangers and other cross-flow tube exchangers, which are often used for example in airconditioning and refrigeration.

\section{Nomenclature}

$A_{d} \quad$ free cross-section surface area in flue gas duct, $\mathrm{m}$

$A_{\text {fin }} \quad$ fin surface area, $\mathrm{m}^{2}$

$A_{r m} \quad$ smooth tube surface area in between the fins, $\mathrm{m}^{2}$

$A_{r} \quad$ smooth tube outer surface area, $\mathrm{m}^{2}$

$d_{\text {in }} \quad$ inner diameter, $\mathrm{m}$

$d_{\text {out }} \quad$ outer diameter, $\mathrm{m}$

$h_{g} \quad$ heat transfer coefficient, flue gas side, $\mathrm{W} / \mathrm{m}^{2} \mathrm{~K}$

$h_{z r} \quad$ weighted heat transfer coefficient, flue gas side, $\mathrm{W} / \mathrm{m}^{2} \mathrm{~K}$

$H_{z}$ fin height, $\mathrm{m}$

$k_{a} \quad$ ash deposit thermal conductivity, $\mathrm{W} /(\mathrm{m} \cdot \mathrm{K})$

$k_{\text {fin }} \quad$ fin thermal conductivity, $\mathrm{W} /(\mathrm{m} \cdot \mathrm{K})$

$k_{w} \quad$ tube material thermal conductivity, $\mathrm{W} /(\mathrm{m} \cdot \mathrm{K})$

$L$ tube length, m

$\mathrm{Nu} \quad$ Nusselt Number

Pr Prandtl Number

$r_{\text {in }} \quad$ inner radius of the tube, $\mathrm{m}$

$r_{\text {out }} \quad$ outer radius of the tube, $\mathrm{m}$

Re Reynolds Number

$s_{z} \quad$ equivalent thickness of the radiative layer, $\mathrm{m}$

$T$ temperature, ${ }^{\circ} \mathrm{C}$

$T_{g} \quad$ flue gas temperature, $\mathrm{oC}$

$T_{s} \quad$ steam temperature, ${ }^{\circ} \mathrm{C}$

$T_{w} \quad$ wall temperature, ${ }^{\circ} \mathrm{C}$

$T_{g, i}^{\prime} \quad$ flue gas temperature at the inlet to the control volume, ${ }^{\circ} \mathrm{C}$

$T_{g, i}^{\prime \prime} \quad$ flue gas temperature at the outlet of the control volume, ${ }^{\circ} \mathrm{C}$

$\Gamma \quad$ gamma function

$\delta_{a} \quad$ ash deposit thickness, $\mathrm{m}$

$\delta_{\text {fin }} \quad$ fin thickness, $\mathrm{m}$

$\eta_{\text {fin }} \quad$ fin efficiency

$\xi \quad$ friction factor for smooth tubes

\section{References}

1. Raghavan V., Combustion Technology. Essentials of Flames Burners (John Wiley \& Sons Ltd., UK, 2016)

2. Ranade V.V., Gupta D.F., Computional Modeling of Pulverized Coal Fired Boilers (CRC Press - Taylor \& Francis Group, Boca - Raton, 2015)
3. Hewitt G.F., Shires G.L., Bott T.R., Process Heat Transfer, CRC Press - Begell House: Boca Raton, 1994)

4. Kakaç S., Liu H., Heat Exchangers: Selection, Rating, and Thermal Design, second ed. (CRC Press -Taylor \& Francis Group: Boca Raton, 2002)

5. Shah R.K., Sekulić D.P., Fundamentals of heat exchanger design (Wiley: Hoboken, 2003).

6. Kuznetsov N. V., Mitor V. V., Dubovskij I. E., Karasina E. S., Thermal Calculations of Steam Boilers. Standard Method (Energy, Moscow, 1973) (in Russian)

7. Lokshin V. A., Peterson D. F., Schwarz A. L., Standard Methods of Hydraulic Design for Power Boilers, (Hemisphere, Washington, 1988)

8. Taler J., Dzierwa P., Taler D., Harchut P., Energy, 92, pp. 160-170 (2015)

9. Dzierwa P., Journal of Thermal Stresses, 39, pp. 874-886 (2016)

10. Qua H.C., Khaw C.C., Tan C.S., Wang X., Ooi J.B., Engineering Failure Analysis, 18, 8, pp. 22012210 (2011)

11. Sagayaraj D., Suresh S., Chandrasekar M., International Journal of Minerals, Metallurgy and Materials, 16, 5, pp. 534-539 (2009)

12. Lowrey S., Sun Z., International Journal of Refrigeration, 60, pp. 38-53 (2015)

13. Stevanovic V.D., Ilic M., Djurovic Z., Wala T., Muszynski S., Gaji I., Energy, 147, pp. $782-798$ (2018)

14. Çengel Y.A., Introduction to Thermodynamics and Heat Transfer 2nd Edition (McGraw-Hill, Hoboken, 2008)

15. Kraus A.D., Aziz A., Welty J., Extended surface heat transfer (Wiley, New York, 2001)

16. Kreith F., Manglik R.M., Bohn M.S., Principles of heat transfer (Seventh Edition, Cengage Learning, Stamford, USA, 2011).

17. Taler J., Duda P., Solving Direct and Inverse Heat Conduction Problems (Springer, Berlin, 2006)

18. Pronobis M., Kalisz S., Wejkowski R., Heat and Mass Transfer, 38, pp. 343-350 (2002)

19. Gnielinski V., International Chemical Engineering, 16, pp. 359-368 (1976)

20. Filonienko G. K., Teploenergetika 1, 4, pp. 40-44 (1954), (in Russian)

21. Taler D., International Journal of Thermal Sciences, 108, pp. 108-122 (2016)

22. Thompson W.J., Atlas for Computing Mathematical Functions, New York, Wiley (1997).

23. Trojan M., Taler D., Fuel 150, pp. 75-87 (2015)

24. Taler D., Trojan M., Dzierwa P., Kaczmarski K., Taler J., International Journal of Thermal Sciences, 129, pp. 320-333 (2018) 